\section{Commentary: Antegrade intravascular ultrasound in acute type $A$ aortic dissection-a new frontier or old news?}

\author{
Irbaz Hameed, MD, ${ }^{\mathrm{a}}$ Clauden Louis, $\mathrm{MD},{ }^{\mathrm{b}}$ and \\ Mario Gaudino, MD, MSCE, $\mathrm{PhD}^{\mathrm{c}}$
}

Central aortic repair for acute type A aortic dissection frequently successfully restores end-organ perfusion. For the unfortunate patient with persistent false lumen and malperfusion following repair, prognosis remains dismal despite aggressive intervention. In this edition of the Jour$n a l$, Alagoz and colleagues ${ }^{1}$ from the University of Texas Health describe their experience with intraoperative antegrade intravascular ultrasound (IVUS) for diagnosing patients with acute type A aortic dissection with suspected visceral malperfusion. They do so by retrospectively reviewing 15 of 192 patients with type A aortic dissection who underwent intraoperative IVUS at their institution based on clinical, imaging, and laboratory judgment.

Multiple imaging modalities can guide perioperative management of acute type A aortic dissection. These include computed tomography angiography (CTA), magnetic resonance imaging, transesophageal echocardiogram and, recently, IVUS. ${ }^{2}$ While IVUS and transesophageal echocardiography are superior to CTA for identifying multiple entries, false lumen slow flow, and incomplete stent apposition, transesophageal echocardiography is superior to IVUS and CTA for detecting endoleaks. The use of IVUS has also been associated with less accurate measure-

From the a Division of Cardiac Surgery, Department of Surgery, Yale School of Medicine, New Haven, Conn; ${ }^{b}$ Department of Cardiothoracic Surgery, University of Rochester, Rochester, NY; and ${ }^{\mathrm{c} D e p a r t m e n t}$ of Cardiothoracic Surgery, Weill Cornell Medicine, New York, NY.

Disclosures: The authors reported no conflicts of interest.

The Journal policy requires editors and reviewers to disclose conflicts of interest and to decline handling or reviewing manuscripts for which they may have a conflict of interest. The editors and reviewers of this article have no conflicts of interest.

Received for publication Sept 7, 2021; revisions received Sept 7, 2021; accepted for publication Sept 10, 2021; available ahead of print Sept 16, 2021.

Address for reprints: Mario Gaudino, MD, MSCE, PhD, Department of Cardiothoracic Surgery, Weill Cornell Medicine, 525 E 68th St, New York, NY 10065 (E-mail: mfg9004@med.cornell.edu).

JTCVS Techniques 2021;10:188-9

2666-2507

Copyright (C) 2021 The Author(s). Published by Elsevier Inc. on behalf of The American Association for Thoracic Surgery. This is an open access article under the CC BY-NC-ND license (http://creativecommons.org/licenses/by-nc-nd/4.0/).

https://doi.org/10.1016/j.xjtc.2021.09.023

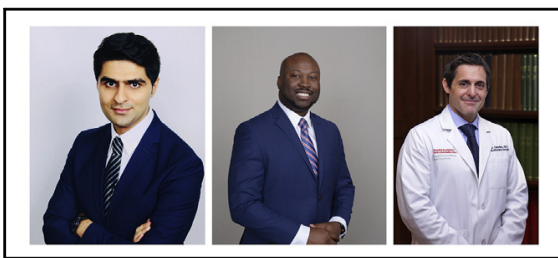

Left to right: Irbaz Hameed, MD, Clauden Louis, MD, and Mario Gaudino, MD, MSCE, PhD

CENTRAL MESSAGE

Intravascular ultrasound may

have a role in the management

of acute type A aortic dissection

with malperfusion syndrome and

is feasible via an antegrade

approach.

ments in tortuous sections of the aorta compared with CTA. ${ }^{3,4}$ Importantly, IVUS remains an invasive imaging strategy with its associated risks. The insertion of the IVUS catheter can cause accidental new entry tears or aortic dissection, particularly in patients with complex pathology. Due to its high cost, routine intraoperative use may also not be feasible across all institutions.

The use of IVUS has previously been described for type $\mathrm{A}$ and $\mathrm{B}$ aortic dissections, but these studies have been limited to retrograde approach via the femoral vessels and small case series. ${ }^{2}$ IVUS via the antegrade approach for type A aortic dissection is not well described, and the technical report presented by the Houston group is a useful addition to current literature on the subject. By demonstrating $100 \%$ technical success in applying antegrade IVUS to these frail patients, they were able to identify 4 patients with persistently collapsed true lumen postoperatively. These patients were amenable to timely further intervention, which mitigated catastrophic consequences. In the patient with acute type A aortic dissection, antegrade IVUS permits inspection of true lumen patency, confirmation of stent graft placement in the true lumen, and inspection of the branch vessels for evidence of dissection. This is achieved without additional arterial access or contrast administration, which is particularly beneficial to patients with renal insufficiency, highly prevalent in the type A aortic dissection population.

In summary, IVUS may have a role in the management of acute type A aortic dissection with malperfusion syndrome via an antegrade approach through the aortic graft. Aortic surgeons and trainees should be trained in performing and 
interpreting IVUS and be able to apply the technology in a safe and minimally invasive manner where necessary. The exact indications of antegrade IVUS versus other imaging modalities in the setting of type A dissection remain to be explored. Until then, the use of IVUS must be carefully considered along with other imaging modalities on a patient-by-patient basis and be performed by experienced operators.

\section{References}

1. Alagoz M, Ikeno Y, Tanaka A, Estrera AL, Afifi RO. Intraoperative antegrade intravascular ultrasound examination in acute type A aortic dissection with suspected visceral malperfusion. J Thorac Cardiovasc Surg Tech. 2021;10: $183-7$.

2. Kpodonu J, Ramaiah VG, Diethrich EB. Intravascular ultrasound imaging as applied to the aorta: a new tool for the cardiovascular surgeon. Ann Thorac Surg. 2008;86:1391-8.

3. Hu W, Schiele F, Meneveau N, Seronde MF, Legalery P, Caulfield F, et al. Value of intravascular ultrasound imaging in following up patients with replacement of the ascending aorta for acute type A aortic dissection. Chin Med J. 2008;121:213943.

4. Hausmann D, Erbel R, AlibelliChemarin MJ, Boksch W, Caracciolo E, Cohn JM et al. The safety of intracoronary ultrasound. A multicenter survey of 2207 examinations. Circulation. 1995;91:62330.

5. Hoshina K, Kato M, Miyahara T, Mikuriya A, Ohkubo N, Miyata T. A retrospective study of intravascular ultrasound use in patients undergoing endovascular aneurysm repair: its usefulness and a description of the procedure. Eur J Vasc Endovasc Surg. 2010;40:559-63. 